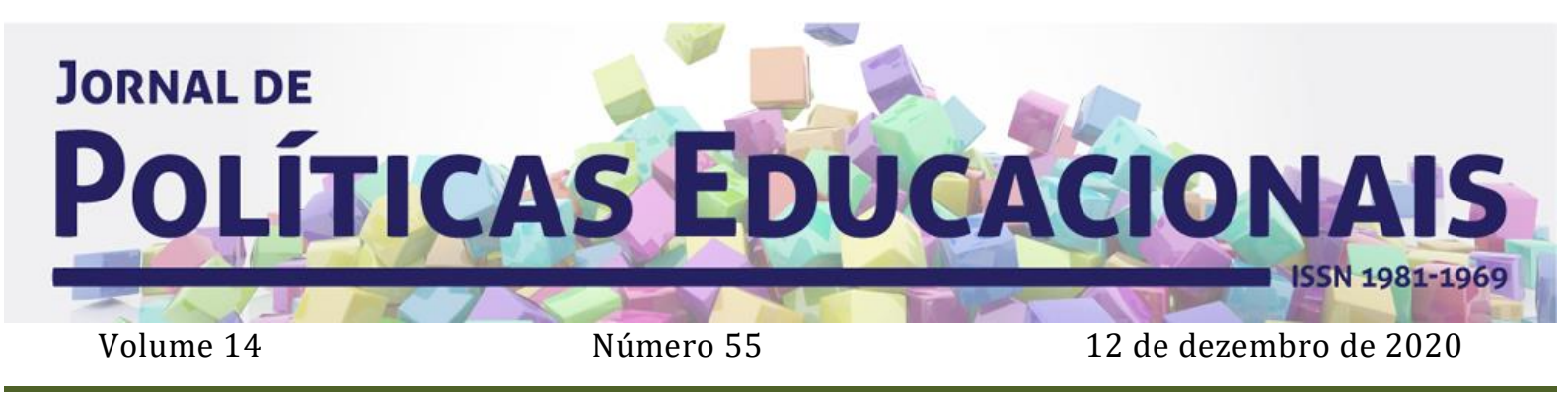

\title{
A Qualidade Educacional: da Agenda 2030 para o desenvolvimento Sustentável ao Grupo de Institutos, Fundações e Empresas (GIFE)
}

\section{THE EDUCATIONAL QUALITY: from the 2030 Agenda for Sustainable Development to the Group of Institutes, Foundations and Enterprises (GIFE)}

\section{LA Calidad Educativa: de la Agenda 2030 para el Desarrollo Sostenible al Grupo de Institutos, Fundaciones y Empresas (GIFE)}

Kelly Letícia Sakata ${ }^{1}$

Citação: SAKATA, K. L. A QUALIDADE EDUCACIONAL: da Agenda 2030 para o desenvolvimento Sustentável ao Grupo de Institutos, Fundações e Empresas (GIFE). Jornal de Políticas Educacionais. V. 14, n. 55. Dezembro de 2020.

http://10.5380/jpe.v14i0.77483

\section{Resumo:}

A partir de pesquisa bibliográfica e análise documental, o presente texto objetiva investigar a perspectiva de qualidade da Educação básica posta em ações e documentos emitidos pelo Grupo de Institutos, Fundações e Empresas (GIFE) a partir da Agenda 2030 para o Desenvolvimento Sustentável da Organização das Nações Unidas (ONU) no que se refere aos Objetivos de Desenvolvimento Sustentável 4 (ODS4). Para tanto, inicia-se com a discussão sobre as bases normativas do conteúdo de qualidade educacional e os conceitos de qualidade que perpassam seu sentido ampliado, após indica-se os desdobramentos da ODS4 no contexto brasileiro. Ao final, problematiza-se a perspectiva de qualidade educacional para a Educação Básica posta pelo GIFE a partir da ODS4. Conclui-se que a perspectiva de qualidade que perpassa o GIFE é a qualidade para resultados, o grupo associa a ODS4 à ODS17, no fomento das parcerias com o setor público, e suas ações são voltadas para a formação de professores e parcerias no âmbito da gestão.

Palavras-chave: Direito Educacional, Qualidade educacional, Agenda 2030 para o Desenvolvimento Sustentável, Objetivos de Desenvolvimento Sustentável 4, Grupo de Institutos, Fundações e Empresas (GIFE).

\footnotetext{
1 Doutoranda pela Universidade Federal do Paraná (UFPR). Mestre em Educação pela Universidade Estadual do Centro-Oeste (UNICENTRO/IRATI-PR). Professora da Universidade Estadual do Centro Oeste (UNICENTO/IRATI/PR). Integrante do Grupo de Pesquisa Estado, Política e Gestão em Educação (UNICENTRO/I) e da Rede de Estudos e Pesquisas sobre Planejamento e Gestão Educacional (UFPR). Irati, PR, Brasil. Orcid: http://orcid.org/0000-0003-4176-0412.E-mail: kelly.l.sakata@hotmail.com
} 


\begin{abstract}
:
Based on bibliographic research and document analysis, this text aims to investigate the perspective of quality of basic education in actions and documents issued by the Group of Institutes, Foundations and Enterprises (GIFE) from the 2030 Agenda for Sustainable Development of the United Nations (UN) as regards the Sustainable Development Goals 4 (SDG4). To this end, it begins with the discussion about the normative bases of the content of educational quality and the concepts of quality that pervade its enlarged meaning, after indicating the unfolding of SDG4 in the Brazilian context. At the end, the perspective of educational quality for Basic Education posed by GIFE from SDG4 is problematized. It is concluded that the perspective of quality that pervades the GIFE is the quality for results, the group associates the SDG4 to the SDG17, in the promotion of partnerships with the public sector, and its actions are aimed at the formation of teachers and partnerships in the scope of management.
\end{abstract}

Keywords: Educational Law, Educational Quality, 2030 Agenda for Sustainable Development, Sustainable Development Goals 4, Group of Institutes, Foundations and Enterprises (GIFE).

\title{
Resumen:
}

A partir de investigación bibliográfica y análisis documental, el presente texto tiene como objetivo investigar la perspectiva de calidad de la Educación básica puesta en acciones y documentos emitidos por el Grupo de Institutos, Fundaciones y Empresas (GIFE) sobre la base de la Agenda 2030 de las Naciones Unidas para el Desarrollo Sostenible (ONU) en relación con los Objetivos de Desarrollo Sostenible 4 (ODS4). Para ello, se inicia con la discusión sobre las bases normativas del contenido de calidad educativa y los conceptos de calidad que atraviesan su sentido ampliado, tras señalarse los despliegues de la ODS4 en el contexto brasileño. Al final, se problematiza la perspectiva de calidad educativa para la Educación Básica puesta por el GIFE a partir de la ODS4. Se concluye que la perspectiva de calidad que atraviesa el GIFE es la calidad para resultados, el grupo asocia a ODS4 a ODS17, en el fomento de las asociaciones con el sector público, y sus acciones están dirigidas a la formación de profesores y asociaciones en el ámbito de la gestión. Palabras-clave: Derecho Educativo, Calidad educativa, Agenda 2030 para el Desarrollo Sostenible, Objetivos de Desarrollo Sostenible 4, Grupo de Institutos, Fundaciones y Empresas (GIFE).

\section{Introdução}

O direito educacional é reconhecido como um dos direitos fundamentais em praticamente todos os países, porém para a sua garantia é preciso que a educação esteja inscrita em lei de caráter nacional. Este direito pode se manifestar "na lei, na jurisprudência, nos usos e costumes jurídicos, nos princípios gerais de direito e no poder negocial" (BOAVENTURA, 1993, p. 175). Estas manifestações são consideradas modos de expressão e de produção do direito.

Neste sentido, a "importância da lei não é identificada e reconhecida como um instrumento linear ou mecânico de realização de direitos sociais. Ela acompanha o desenvolvimento contextuado da cidadania em todos os países" (CURY, 2002, p. 247). Assim, possui uma dimensão de correlações de forças entre atores sociais distintos, em que os avanços são marcados por movimentos de lutas de viés progressista com princípios de igualdade. 
No Brasil o reconhecimento da educação como direito público subjetivo ocorreu a partir de disputas entre diferentes concepções e se materializou pela Constituição Federal de 1988 (CF/1988). Ela determina, para além da garantia de acesso e a permanência do ensino fundamental, no Art. 206 os princípios basilares em que o ensino será ministrado, entre eles a "garantia do padrão de qualidade" (BRASIL, 1988).

Nesta direção, o objetivo deste artigo é investigar e compreender qual a perspectiva de qualidade da Educação básica proposta pelo Grupo de Institutos, Fundações e Empresas (GIFE) o qual mantém parcerias e projetos com o setor público. Esta análise compreende-se a partir da Agenda 2030 para o desenvolvimento Sustentável da Organização das Nações Unidas (ONU) no seu Objetivo de Desenvolvimento Sustentável 4 (ODS4): "Assegurar a educação inclusiva e equitativa e de qualidade, e promover oportunidades de aprendizagem ao longo da vida para todas e todos" (ONU, 2016).

A partir de pesquisa bibliográfica e análise documental, na primeira seção discutese o entendimento do conteúdo de qualidade educacional no contexto brasileiro e o conceito de qualidade posto pela Campanha Nacional pelo Direito à Educação (CNDE) e pelos autores Adams (1993), Tomasevski (2004) e Ximenes (2014a, 2014b). Após, indicase a proposta de qualidade posta pela ODS4 da Agenda 2030 para o desenvolvimento Sustentável e seu desdobramento no contexto brasileiro. Ao final, problematiza-se a perspectiva do GIFE no bojo da relação com o âmbito público a partir da OSD4 no que se refere às indicações de qualidade educacional.

\section{Qualidade como princípio no campo do direito educacional}

Atualmente, com o paradigma da cultura da avaliação e com a presença crescente do privado mercantil definindo a educação pública (PERONI, 2018), o conteúdo da qualidade passa ser objeto de disputa entre grupos distintos da sociedade. Segundo Gentili e Silva (1994), a qualidade educacional passa a ser uma bandeira utilizada por todos os grupos e atores sociais, com significados distintos. Nesta direção, emerge tensionamentos entre sistemas alternativos de sociedade e embates por recursos, em que é difundido pelos grupos hegemônicos o entendimento da qualidade educacional de modo desvinculado às condições mínimas de insumo. 
Sob este prisma, desloca-se do âmbito privado para o público os paradigmas da "gestão para o resultado" e a "qualidade total". Neste modelo, o discurso de igualdade neoliberal diminui passando a vigorar o discurso de qualidade, especialmente da qualidade de aprendizagem. Esta nova postura localiza-se num contexto mais amplo das mudanças de sociabilidade capitalista, a qual emerge pelo rompimento do regime de acumulação taylorista-fordista-keynesiano e pela revolução técnico-científica (GENTILI; SILVA, 1994).

Na contramão desta proposta, em 2007 a Campanha Nacional pelo Direito a educação (CNDE), uma rede que articula centenas de grupos e entidades que atuam em defesa da escola pública, cria o Custo Aluno Qualidade (CAQ) e o Custo Aluno QualidadeInicial (CAQi). O CAQ é um parâmetro que consiste num mecanismo que une qualidade, controle social e financiamento considerados adequados à educação. Ele considera os insumos necessários na garantia de um padrão de qualidade, propondo a aproximação dos custos do Brasil em relação aos países mais desenvolvidos. O CAQi é um indicador que garante um parâmetro mínimo de qualidade na educação (CAMPANHA NACIONAL PELO DIREITO À EDUCAÇÃO, 2018; 2020; CARREIRA; PINTO, 2007).

A CNDE visualiza "na proteção jurídica ao princípio da qualidade uma exigência de garantia de igualdade de base quanto às condições de funcionamento das escolas (insumos) e à qualificação dos processos educacionais" (XIMENES, 2014a, p. 1029). Deste modo, os insumos que integram o CAQi estão organizados nas dimensões: estrutura $e$ funcionamento; trabalhadoras e trabalhadores da educação; gestão democrática; e, acesso e permanência. Assim, para realizar o cálculo do CAQi considera-se

[...] condições como tamanho das turmas, formação dos profissionais da educação, salários e carreira compatíveis com a responsabilidade dos profissionais da educação, instalações, equipamentos e infraestrutura adequados, além de insumos como laboratórios, bibliotecas, quadras poliesportivas cobertas, materiais didáticos, entre outros, tudo para cumprir o marco legal brasileiro (CAMPANHA NACIONAL PELO DIREITO À EDUCAÇÃO, 2018, p. 17).

Este movimento tensiona a materialidade das indicações legais do princípio e de padrão de qualidade, os quais deveriam ser assegurados pelo Estado. A CF/1988 assinala no art. $211 \S 1^{\mathrm{o}}$ e no art. 212. $\S 3^{\circ}$, respectivamente, o "padrão mínimo de qualidade do ensino mediante assistência técnica e financeira" e "garantia de padrão de qualidade e equidade, nos termos do plano nacional de educação" (BRASIL, 1988). A Lei de Diretrizes 
e Bases da Educação (LDBEN/1996) declara no inciso IX do artigo 4oㅜ o estabelecimento de "padrões mínimos de qualidade de ensino, definidos como a variedade e quantidade mínimas, por aluno, de insumos indispensáveis ao desenvolvimento do processo de ensino-aprendizagem" (BRASIL, 1996).

Outro movimento voltado para a materialidade de um padrão de qualidade foi verificado pelo Conselho Nacional de Educação (CNE), no Parecer CNE/CB no 8/2010. Ele estabelece normas para aplicação do inciso IX do artigo 4ํ da LDBEN/1996, já citado e definiu o CAQ/CAQi como uma estratégia para vencer desigualdades sendo calculado a partir de insumos educacionais essenciais. Os padrões foram definidos, entre outros, como: professores qualificados; existência de apoio técnico e administrativo; condições de infra-estrutura nas creches e escolas; e, relação adequada de alunos por turma (BRASIL, 2010. Ele foi anulado pelo parecer CNE/CEB no 3/2019. 0 que constata a falta de prioridade do governo Luiz Inácio Lula da Silva (2003-2011) sobre esta questão.

Na mesma direção normativa, o Plano Nacional de Educação (PNE 2014-2024) Lei 13.005 de 2014, em seu art. $2^{\circ}$, IV indica "a melhoria da qualidade da educação" e no VIII sinaliza o "estabelecimento de meta de aplicação de recursos públicos em educação como proporção do Produto Interno Bruto - PIB, que assegure atendimento às necessidades de expansão, com padrão de qualidade e equidade" (BRASIL, 2014).

Desta forma, há um movimento de reestruturação da Educação Básica neste período, pois o CAQ é incluído no PNE 2014-2024, especialmente, em quatro estratégias da meta 20 , cujo objetivo é alcançar até o final do período, o montante de $10 \%$ do Produto Interno Bruto (PIB) do Brasil investido em educação. As estratégias que mencionam o CAQ são 20.6, 20.7, 20.8 e 20.10. As quais indicam, respectivamente: a implementação do CAQ; a definição do CAQ no prazo de três anos; e, a complementação de recursos financeiros a esfera administrativa que não conseguir atingir o proposto (BRASIL, 2014).

No entanto, com a saída da Dilma Rousseff (2011-2016) da presidência e a entrada do governo reacionário de Michel Temer (2016-2019), que tem sequência no atual governo, emerge um pacote de medidas econômicas ${ }^{2}$ que retiram direitos básicos. Dentre eles, a Emenda Constitucional (EC) no 95/2016 que estabelece um congelamento de

\footnotetext{
${ }^{2}$ As políticas de implementação da Educação em Direitos Humanos (EDH) vêm sendo desmontadas. Um exemplo é a extinção da Secretaria de Educação Continuada, Alfabetização, Diversidade e Inclusão (SECADI), pelo Decreto 9.465, de 2 de janeiro de 2019 e a desvinculação do Comitê Nacional de EDH do MEC e absorção pelo Ministério da Mulher, da Família e dos Direitos Humanos, em que retiram, a EDH da agenda política nacional da educação (CAMPANHA NACIONAL PELO DIREITO À EDUCAÇÃO, 2020).
} 
recursos para educação, saúde e assistência social até 2036, a qual é o obstáculo atual para a universalização do acesso à educação de qualidade no país por colocar em xeque o cumprimento das metas e estratégias estabelecidas PNE 2014-2024. Para além disso, a falta de implementação do Regime de Colaboração instituído tensiona a não concretude deste padrão de qualidade, inscrito nos documentos citados.

Neste contexto, acirrou-se a discussão sobre a inclusão do CAQ/CAQi no Fundo de Manutenção e Desenvolvimento da Educação Básica e de Valorização dos Profissionais da Educação ${ }^{3}$ (Fundeb), por meio da Proposta de Emenda à Constituição (PEC) n ${ }^{\circ} 26$ de 2020. Ela foi aprovada e gerou a Emenda Constitucional no 108 de 26/08/2020, a qual determina que o Fundeb seja instituído em caráter permanente. Este movimento, é um exemplo da disputa em torno do conteúdo da política educacional e em particular do entendimento sobre qualidade e dos fundos e insumos que a perpassam.

Num sentido ampliado, ao tentar definir qualidade educacional, segundo Adams (1993) o conceito perpassa por seis dimensões: reputação das instituições; recursos $e$ insumos; processo; conteúdo; resultados; e, valor agregado. A reputação das instituições prevalece na avaliação de instituições de ensino e refere-se a entrada e a saída dos estudantes nas instituições. Os recursos e insumos, o qual se aproxima do CAQ, refere-se aos recursos financeiros, número e formação de professores e extensão das instalações. 0 processo sugere que para além dos insumos ou resultados, a natureza da interação intrainstitucional de alunos, professores e outros educadores é valorizada. 0 conteúdo reflete o corpo de conhecimento, habilidades ou informação referente ao currículo escolar. A dimensão resultados, como visto, é comumente utilizado nas decisões políticas em que utiliza-se medidas de definição para as habilidades cognitivas, taxas de ingresso em níveis posteriores de ensino, renda e status educacional. Por fim, o valor agregado está ligado ao impacto, influência ou efeito das instituições nos estudantes.

Outrossim, Ximenes (2014a, 2014b), partindo da teoria dos direitos fundamentais como princípios e dos escritos de Tomasevski ${ }^{4}$ (2004), propõe um marco conceitual sobre o conteúdo amplo do direito à qualidade posto no art. 206 da CF/1988, o qual refere-se ao padrão de qualidade. $\mathrm{O}$ autor indica a proposição das quatro dimensões de qualidade educacional; a disponibilidade que visa assegurar a educação gratuita e obrigatória e a

\footnotetext{
${ }^{3}$ O Fundeb atual expira no dia 31 de dezembro de 2020.

${ }^{4}$ Os indicadores definidos por Tomasevskiw (2006) foram incorporados à interpretação oficial do Comitê de Direitos Econômicos, Sociais e Culturais da ONU.
} 
generalização da educação não obrigatória; a acessibilidade, a qual indica a obrigação estatal atrelada ao direito civil e político em que busca maximizar a igualdade de acesso e permanência; a aceitabilidade que almeja a adequação e a qualidade no que se refere aos livros escolares, métodos de ensino e aprendizado, que são modificados tornando a educação aceitável para todos; e, por fim, a adaptabilidade a qual indica a adaptação o pluralismo de concepções pedagógicas para maximizar as liberdade no ensino (TOMASEVSKI, 2004; XIMENES, 2014a, 2014b).

0 pesquisador supracitado, contextualiza que convergente com as reformas neoliberais, o direito social "[...] em sua totalidade passa a ser ideologicamente identificado em sua parcela 'essencial' ou 'mínima', acima da qual a obrigação estatal deixaria de ser uma pretensão juridicamente protegida, substituída pela oferta de serviços no mercado" (XIMENES, 2014b, p. 107). Em outras palavras, quando não se indica um conteúdo de qualidade mínimo aplicável há o afastamento quanto as obrigações do Estado. Nesta direção, o autor propõe dois aspectos da qualidade educacional, o interno, referente as condições de oferta, gestão e processos educativos e o externo, que indica o acesso, permanência e conclusão. Assim, para uma melhor visualização o quadro abaixo dispõe sobre as dimensões da qualidade educacional entendida de forma mais ampla:

Quadro 01: Dimensões da qualidade nos autores estudados Brasil - 2020

\begin{tabular}{|l|l|}
\hline AUTORES & DIMENSÕES \\
\hline CAMPANHA NACIONAL PELO & Estrutura e funcionamento \\
\cline { 2 - 2 } $\begin{array}{l}\text { DIREITO À EDUCAÇÃo } \\
\text { (2018), CARREIRA E PINTO }\end{array}$ & $\begin{array}{l}\text { Trabalhadores (as) da } \\
\text { educação }\end{array}$ \\
\cline { 2 - 2 } & Gestão democrática \\
\cline { 2 - 2 } & Acesso e permanência \\
\hline ADAMS (1993) & Reputação das instituições \\
\cline { 2 - 2 } & Recursos e insumos \\
\cline { 2 - 2 } & Processo \\
\cline { 2 - 2 } & Conteúdo \\
\cline { 2 - 2 } & Resultados \\
\cline { 2 - 2 } & Valor Agregado \\
\hline TOMASEVSKI (2004) E & Disponibilidade \\
\cline { 2 - 2 } XIMENES (2014A, 2014B) & Acessibilidade \\
\cline { 2 - 2 } & Aceitabilidade \\
\cline { 2 - 2 } & Adaptabilidade \\
\hline
\end{tabular}

Fonte: Organizado pela autora (CAMPANHA NACIONAL PELO DIREITO À EDUCAÇÃO, 2018; CARREIRA; PINTO, 2007; TOMASEVSKI, 2004; XIMENES, 2014a, 2014b; ADAMS, 1993). 
Como observado, o direito a uma educação de qualidade numa perspectiva ampla pressupõe a exigência, frente ao Estado, de medidas de serviços e suporte críticos que incluam recursos no sentido de superar e promover oportunidades justas e iguais a todas as crianças, para além da dimensão de acesso e permanência. Neste bojo, problematizase: qual o paradigma de qualidade emergente a nível global?

\section{Agenda 2030 para o desenvolvimento Sustentável, ODS4 e o contexto brasileiro}

No debate acerca da qualidade educacional, a nível global, identifica-se as influências das agências internacionais nas políticas nacionais e internacionais o que pode gerar formas diferenciadas de regulação. Este aspecto pode ser identificado em diversos países, porém cada Estado dispõe de autonomia, e cada contexto possui especificidades no que concerne à educação e qualidade educacional independente da pressão das tendências globalizantes (AKKARI, 2011). Neste sentido, a ideia de que a nossa política educacional seja "determinada" por uma agenda internacional não vislumbra contradições presentes e seus conflitos ideológicos.

Nesta direção, a Agenda 2030 para o Desenvolvimento Sustentável consiste em um aprimoramento dos Objetivos de Desenvolvimento do Milênio (ODMS), os quais foram adotados em 2001 e Derivados da Declaração do Milênio (2000), compromisso assinado por 192 países. Os ODMS tornaram-se um ponto central da agenda de desenvolvimento internacional com base no desenvolvimento humano. Os ODMS possuiam dois eixos centrais a gestão por resultados e a perspectiva do desenvolvimento humano, os quais vieram da Organização para Cooperação e Desenvolvimento Econômico (OCDE) em 1996 (HULME, 2010).

No âmbito educacional, em 1992, emergiu a promoção da Educação para o Desenvolvimento Sustentável (EDS) atrelada ao Programa de Ação Global (GAP) sobre EDS, que decorreu de 2015 a 2019. A EDS desde estão foi reconhecida como um elementochave da educação de qualidade e um facilitador crucial para o desenvolvimento sustentável. Nesta direção, os ODS adotados pela comunidade global atual reconhecem a importância da educação para atingir suas metas até 2030.

Deste modo, a ONU, baseando-se na Declaração Universal dos Direitos Humanos indicou na Agenda 2030 para o Desenvolvimento Sustentável, 17 ODS, 169 metas e 230 indicadores, como um plano de ação global. Ela ressalta que os ODS são ferramentas de 
planejamento, a médio e longo prazo, que viabilizam o alinhamento nacional de políticas sociais, ambientais e econômicas. Assim, é considerado um quadro para orientar políticas públicas em nível mundial (ONU, 2016). Outrossim, a ODS4 indica "assegurar a educação inclusiva e equitativa de qualidade, e promover oportunidades de aprendizagem ao longo da vida para todos" (ONU, 2016). Este objetivo é constituído por 10 metas, as quais indicam, de forma geral, aspectos como: resultados; eficácia; equidade; gratuidade; acesso; permanência; conhecimentos básicos (português e matemática); desenvolvimento sustentável e integral (na primeira infância); infraestrutura física; segurança; e, formação específica aos professores.

A maioria das metas dos ODS4, quando proposta em 2015, foram previstas por ações de governo brasileiro nos âmbitos federal, estadual e municipal. Sob este prisma, o principal instrumento de apoio ao ODS 4 é o PNE (2014-2024), pois representa o instrumento para estabelecer diretrizes às políticas públicas educacionais brasileiras. 0 cumprimento das metas do referido plano garantiria que 70\% das metas do ODS 4, relativas à educação, fossem atendidas até 2024, conforme aponta a figura 1 do Instituto

\begin{tabular}{|c|c|c|c|c|c|c|c|c|c|c|}
\hline ODS & 1 & 2 & 3 & 4 & 5 & 6 & 7 & $a$ & $b$ & $c$ \\
\hline PNE & $\begin{array}{c}2,3,6 \\
\mathrm{e} 7\end{array}$ & 1 & $\begin{array}{c}11,12,13 \\
\mathrm{e} 14\end{array}$ & $\begin{array}{c}9,11,12, \\
13 \mathrm{e} 14\end{array}$ & 4 e 8 & 4,5 e 8 & BNCC $^{1}$ & Inep $^{2}$ & NC & $\begin{array}{c}15,16,17 \\
\text { e } 18\end{array}$ \\
\hline
\end{tabular}

de pesquisa e econômica aplicada (IPEA, 2019).

Figura 01: Metas dos ODS e suas contrapartidas em metas do PNE-2019

Fonte: IPEA (2019). Notas: 1 Base Nacional Comum Curricular (BNCC). 2 Instituto Nacional de Estudos e Pesquisas Educacionais Anísio Teixeira (Inep).

Contudo, como já sinalizado, com a EC 95/2016 a concretude destas metas esta comprometida. Segundo o "IV Relatório Luz da Sociedade Civil da Agenda 2030 de desenvolvimento sustentável" da CNDE (2020) a Auditoria do Tribunal de Contas da União em 2020 apontou o baixo nível de governança do Ministério da Educação na condução de políticas públicas educacionais como entrave para o alcance das metas do PNE (2014-2024). Para além disso, no documento "A situação do direito à educação e do Objetivo de Desenvolvimento Sustentável 4" (CAMPANHA PELO DIREITO À EDUCAÇÃO, 2019) indica ainda que cresceu o número de propostas para reduzir o direito à educação, tais como a de privatização e de oferta de educação básica pública à distância, ideias que são mobilizadas por uma parcela do setor privado. Todo este movimento contraria a previsão de todas as metas do ODS4. 
Nesta direção, ao analisar o conceito de qualidade proposto pelo ODS4, verifica-se por meio das metas e dos documentos: "Transformando Nosso Mundo: a Agenda 2030 para o Desenvolvimento Sustentável; e Educação 2030" (ONU, 2016) e "Declaração de Incheon e Marco de Ação para a implementação do Objetivo de Desenvolvimento Sustentável 4" (UNESCO, 2016), que o entendimento da qualidade educacional é permeado por contradições.

Sob este prisma, a qualidade educacional é relacionada a princípios amplos como: acesso; igualdade (tanto de gênero quanto social); paz, justiça; crescimento econômico sustentado; resultados da aprendizagem; participação; recursos; monitoramento; desenvolvimento de habilidades; formação e remuneração de professores, eficiência, entre outros (ONU, 2016; UNESCO, 2016). A educação de qualidadefa parte da "agenda de educação transformadora", a qual enfrenta "todas as formas de exclusão e marginalização, bem como disparidades e desigualdades no acesso, na participação e nos resultados de aprendizagem" (UNESCO, 2016, p. 7). Deste modo, identifica-se que a educação 2030:

[...] deve ser vista hoje dentro do contexto mais amplo de desenvolvimento. Os sistemas educacionais precisam ser relevantes e responder prontamente a mercados de trabalho que mudam com rapidez, assim como a avanços tecnológicos, urbanização, migração, instabilidade política, degradação ambiental, riscos e desastres naturais, competição por recursos naturais, desafios demográficos, desemprego global crescente, persistência da pobreza, aumento das desigualdades e ameaças crescentes à paz e à segurança (UNESCO, 2016, p. 25).

Para a materialização desta agenda inferiu-se como abordagens estratégicas: estabelecer parcerias eficazes e inclusivas (especialmente com o setor privado); aprimorar políticas educacionais e a forma como elas funcionam em conjunto; garantir sistemas educacionais equitativos, inclusivos e de qualidade para todos; mobilizar recursos para um financiamento adequado da educação; e garantir monitoramento, acompanhamento e revisão de todas as metas. Por fim, os documentos ressaltam que o papel do Estado é de "regular padrões, melhorar a qualidade e reduzir disparidades entre regiões, comunidades e escolas" (UNESCO, 2016, p. 57).

Neste sentido, o conceito de qualidade está atrelado ao discurso de viés progressista e amplo vinculado ao progresso e desenvolvimento econômico sustentado. A contradição identificada é que este discurso acompanha a concepção de educação e qualidade a serviço do desenvolvimento econômico sob a "roupagem" sustentável e sob contornos da teoria do capital humano. Assim, verifica-se que 
Na versão contemporânea de desenvolvimento, o capitalismo adota a narrativa humanitária. Todavia, por mais que tentem adorná-lo, a realidade dinâmica expõe suas contradições, especialmente em momentos de grandes crises, como a pandemia provocada pelo COVID 19 que estamos vivendo. Os apelos deixam evidentes os interesses de classe: enquanto a maioria luta para salvar a vida humana, a ínfima minoria convoca os trabalhadores a salvar a economia, evidenciando que quem produz a riqueza é o trabalho (SHIROMA; ZARDINI, 2020, p. 712).

Nesta direção, a materialização de uma educação de qualidade no âmbito educacional brasileiro, perpassa por muitos desafios. 0 grande desafio é relacionado ao conjunto de implicações relacionado ao papel do Estado como propulsor da garantia do direito à educação, pois ele está aberto "à legitimação de uma pluralidade de concepções que vem disputando a hegemonia sobre os rumos da política educacional no país e, consequentemente, também as opções de regulamento legislativa" (XIMENES, 2014b, p. 101).

Desta forma, mesmo havendo normativas e indicações teóricas em torno da qualidade educacional sob uma perspectiva ampliada, a qual ultrapassa os recursos e insumos, seu conteúdo é tensionado por múltiplos grupos de interesses que, por vezes, podem possuir critérios de qualidades estreitos que integram dimensões específicas de qualidade (ADAMS, 1993). Assim, na próxima seção problematizar-se-á a perspectiva de qualidade para a Educação Básica proposta pelo GIFE a partir da OSD4.

\section{O GIFE e a ODS4: indicações no contexto brasileiro}

O GIFE denomina-se uma associação de institutos, fundações ou empresas dos investidores sociais do Brasil. Emergiu como grupo informal em 1989 e foi instituído como organização sem fins lucrativos, em 1995. Intitula-se uma rede marcada pela diversidade de seus associados, tanto na origem - podendo ser empresarial, familiar, independente ou uma organização comunitária - quanto em seus temas e formas de atuação. São atualmente 161 associados que, eles ressaltam, somados, injetam por volta de $\mathrm{R}$ \$ 2,9 bilhões por ano na área social, operando projetos próprios ou viabilizando os de terceiros. Ele dispõe que seu papel central é gerar conhecimento a partir de articulações em rede para aperfeiçoar o ambiente político institucional do investimento 
social e ampliar a "qualidade, legitimidade e relevância" da atuação dos investidores sociais privados (GIFE, 2020).

Nesta atuação, indicam oito agendas estratégicas prioritárias que os guiam: 1 . Alinhamento do investimento social às políticas públicas; 2. Alinhamento entre investimento social e o negócio; 3. Ampliação da doação no investimento social privado; 4. Avaliação; 5. Comunicação; 6. Fortalecimento das organizações da sociedade civil; 7. Governança e Transparência; e, 8. Negócios de impacto social.

As agendas 1, 2, 7 e 8 possuem aproximação com o setor público educacional. Na agenda 1, apontam parcerias com órgãos públicos, em que 71\% dos investidores sociais estabelecem parcerias com órgãos de administração pública direta. Os órgãos mais frequentes são prefeituras, secretarias e ministérios (com 45\%), atrás somente de organizações da sociedade civil, comunitária e de base (50\%) (GIFE, 2020). 0 GIFE indica, ainda, que o Investimento Social Privado (ISP) não tem relevância apenas na formulação e elaboração de soluções e práticas de aprimoramento e inovação nas políticas públicas, mas também na cooperação para apoiar o funcionamento melhorado da gestão pública.

Sob este prisma, no contexto atual das políticas educacionais brasileiras, a partir do discurso sobre as vantagens do público não estatal, o "Estado não deixou de ser responsável por oferecer serviços públicos à população, mas se alterou a concretização dessa responsabilidade" (SHIROMA, EVANGELISTA, 2014, p. 23). Ou seja, a forma de oferta e implementação dos serviços públicos educacionais inclui o terceiro setor. Este cenário perpassa as transformações do papel do Estado e a emergência de configurações diferenciadas de se pensar e desenvolver as políticas e gestão públicas.

Neste contexto, para identificar a perspectiva de qualidade educacional proposta pelo GIFE a partir da Agenda 2030 para o Desenvolvimento Sustentável, especificamente a ODS4, foram identificadas algumas ações e selecionados ${ }^{5}$ documentos:

Quadro 2: Ações e Documentos emitidos pelo GIFE no desenvolvimento da ODS4 - 2020

\begin{tabular}{|l|l|}
\hline AÇÕES/ANO & RESUMO \\
\hline Mapeamento das & Desafio: Implementação de políticas públicas baseadas em \\
principais oportunidades & evidências para o enfrentamento dos desafios educacionais. \\
e desafios para o setor & Oportunidades: Expansão de iniciativas inovadoras para além do eixo \\
em 2020, alinhados às & $\begin{array}{l}\text { Rio-São Paulo. Aumento do engajamento da sociedade em } \\
\text { programas e projetos capazes de promover o alcance dos ODS. }\end{array}$ \\
\hline
\end{tabular}

\footnotetext{
${ }^{5}$ Os documentos e ações foram selecionados a partir de uma busca no site da GIFE, especificamente nas notícias sobre as ações das ODS e na biblioteca virtual do investimento social (SINAPSE).
} 


\begin{tabular}{|c|c|}
\hline & $\begin{array}{l}\text { ealização de iniciativas em áreas como cultura, desenvolvimento } \\
\text { omunitário e educação no contexto da Economia Criativa. }\end{array}$ \\
\hline Seminário "Parcerias & O evento marcou o lançamento do Projeto de Fortalecimento da Rede \\
\hline Multisetoriais para os & Estratégia ODS, coordenado pela Fundação Abrinq em parceria com a \\
\hline ODS: o desafio da & Agenda Pública, a Confederação Nacional de Municípios e a Frente \\
\hline & Nacional de Prefeitos e financiado pela União Europeia no Brasil. Para \\
\hline lades" / 2019 & $\begin{array}{l}\text { além, estiveram presentes: Instituto Ethos; Oxfam Brasil; Rede Brasil } \\
\text { do Pacto Global }\end{array}$ \\
\hline $\begin{array}{l}\text { Rede de Estratégias ODS } \\
\text { / } 2019\end{array}$ & $\begin{array}{l}\text { A Estratégia ODS é uma coalizão que reúne organizações } \\
\text { representativas da sociedade civil, do setor privado, de governos locais } \\
\text { e da academia o qual o GIFE faz parte. Com o propósito de ampliar e } \\
\text { qualificar o debate a respeito dos ODS no Brasil e de mobilizar, } \\
\text { discutir e propor meios de implementação efetivos para essa agenda. }\end{array}$ \\
\hline & Investimento Social Privado, Sociedade e Desenvolvimento foi o tema \\
\hline $\begin{array}{l}\text { Social } \\
/ 2018\end{array}$ & $\begin{array}{l}\text { da Jornada ISP. Investidores sociais e representantes do poder público, } \\
\text { organismos internacionais e organizações da sociedade civil estiveram } \\
\text { para refletir sobre o ISP no fortalecimento da sociedade civil e na } \\
\text { implementação da Agenda 2030, da ONU. Objetivo: Aprofundar } \\
\text { parcerias e alcançar os ODS estão entre as principais propostas da } \\
\text { Plataforma de Filantropia. }\end{array}$ \\
\hline $\begin{array}{l}\text { Plataforma } \\
\text { Filantropia ODS } \\
\text { uma estratégia paril: } \\
\text { implementação } \\
\text { Agenda } 2030 / 2018\end{array}$ & $\begin{array}{l}\text { É uma iniciativa global que conecta filantropia a conhecimento e redes } \\
\text { que podem aprofundar a cooperação, alavancar recursos e } \\
\text { aumentar o impacto, direcionando os ODS a um planejamento de } \\
\text { desenvolvimento nacional. Trata-se de uma interface global que } \\
\text { facilita a otimização de recursos dos parceiros, permitindo uma } \\
\text { colaboração efetiva com o grande ecossistema de desenvolvimento nos } \\
\text { países. }\end{array}$ \\
\hline $\begin{array}{l}\text { Agenda } 2018 \text { e próximos } \\
\text { passos } \\
\text { Educação de Qualidade / } \\
2017\end{array}$ & $\begin{array}{l}\text { O ISP investe muito em educação, mas não está conseguindo obter } \\
\text { os resultados na velocidade que gostaria. Os desafios não estão na } \\
\text { sensibilização do setor para o tema, mas em atuar na articulação do } \\
\text { setor, tanto entre si, quanto com os outros atores que compõem o } \\
\text { ecossistema da Educação, como poder público, OSCs etc., para } \\
\text { entender como promover um maior impacto agregado. }\end{array}$ \\
\hline DOCUMENTOS/ANO & RESUMO \\
\hline Censo GIFE 2018 / 2019 & $\begin{array}{l}\text { Pesquisa bienal quantitativa, auto declaratória e voluntária, que } \\
\text { fornece um panorama sobre recursos, estrutura, formas de } \\
\text { atuação e estratégias das empresas e dos institutos e fundações } \\
\text { empresariais, familiares e independentes que destinam recursos } \\
\text { privados para projetos de finalidade pública. A educação é a principal } \\
\text { área de atuação, com } 80 \% \text { das menções os Institutos e Fundações } \\
\text { independentes são os que mais incorporam os ODS em suas } \\
\text { estratégias. }\end{array}$ \\
\hline $\begin{array}{l}\text { Filantropia e os } \text { ODS: o } \\
\text { envolvimento r do } \\
\text { investimento social } \\
\text { privado brasileiro na } \\
\text { agenda de } \\
\text { desenvolvimento global. } \\
\text { (PNUD) / } 2017 \text { r }\end{array}$ & $\begin{array}{l}\text { Ele ilustra como os ODS podem avançar no campo filantrópico ao } \\
\text { impulsionar parcerias transformadoras, quando novas ideias e } \\
\text { perspectivas são combinadas e aumentam o impacto geral. }\end{array}$ \\
\hline
\end{tabular}

Fonte: Elaborado pela autora (GIFE, 2020; FERRETI; BARROS; SANTIAGO, 2019; PNUD, 2017, grifos nosso). 
A partir da análise das ações e documentos selecionados, verifica-se que a agenda do GIFE está alinhada a Agenda 2030 para o Desenvolvimento Sustentável. O documento “Censo GIFE 2018” (FERRETI; BARROS; SANTIAGO, 2019) indica que (55\%) das organizações consideram os ODS como referência para a definição de estratégias de atuação e apenas 1\% não tem familiaridade com os ODS, o que indica que essa é uma agenda bastante difundida no GIFE.

O ODS4 é o mais incorporado entre as organizações do grupo e o que recebe mais Investimento social privado - ISP (FERRETI; BARROS; SANTIAGO, 2019; PNUD, 2017), contudo a educação é vista como uma oportunidade de retorno para este investimento e, especialmente nas ações identificadas, há o direcionamento a uma educação de qualidade atrelada ao ODS17, o qual incentiva "as parcerias multissetoriais para a mobilização e compartilhamento de conhecimento, expertise, tecnologia e recursos financeiros" (ONU, 2016). Nesta direção, os documentos reforçam que é no campo da educação que as empresas do grupo estão mais avançadas no desenvolvimento dos ODS, sendo que 39\% dos projetos desenvolvidos relacionam-se diretamente com o ODS 4 (PNUD, 2017).

Desta forma, por meio de suas relações entre o âmbito público promovem o discurso de qualidade atrelado aos resultados em avaliações. Para além, a avaliação interna das organizações emerge com grande importância, assim é pontuado que

[...] as empresas têm se deparado com diversos desafios como, por exemplo: reorientar os projetos em curso e alcançar a escala necessária; garantir recursos para novos projetos; engajar as diversas unidades da empresa; e gerar as informações e indicadores indispensáveis à avaliação dos resultados (PNUD, 2017, p. 54).

Neste sentido, suas principais ações são relacionadas a formação de professores e gestores e em parcerias e projetos com o âmbito da gestão, nestes casos há um direcionamento e estreitamento curricular alinhados à perspectiva de cada instituto/fundação. Identificou-se nas ações realizadas que a discussão sobre recursos $e$ insumos ocorre na defesa de boas práticas em localidades de baixa renda, as quais servem de exemplo de prática.

Assim, as dimensões de qualidade emergentes, as quais vimos na primeira seção, foram: resultados, trabalhadores da educação e conteúdo (ADAMS, 1993). Em que o resultado é o principal parâmetro de qualidade, divulga-se práticas de "excelência" para os professores driblarem as condições de trabalho e o estreitamento curricular, o qual é 
focado em disciplinas que são indicadas nas avaliações externas. Para além, emerge um tensionamento para o direcionamento das políticas públicas educacionais pelo GIFE, por meio da difusão e propagação das parcerias entre o público e o privado como garantia da "qualidade educacional".

Esta análise vai ao encontro dos estudos de Peroni (2018) e Adrião e Silva (2020) as quais indicam que a garantia do acesso à educação pública no Brasil foi ampliada, no entanto houve a presença cada vez maior do privado mercantil definindo a educação pública. Desta forma o Estado continua sendo o responsável pelo acesso, mas o conteúdo pedagógico e de gestão da escola é cada vez mais determinado por instituições que introduzem a lógica mercantil, as quais entendem o âmbito educacional como uma oportunidade e estratégia de negócios.

Desta forma, o GIFE justifica sua ação na contribuição para a qualidade da escola pública, contudo, a qualidade não é a indicada na ODS4. A qualidade é a do paradigma de resultado, que como visto é uma visão estreita de qualidade educacional (ARAUJO, 2007; ADAMS, 1993). Neste contexto, fica-se claro que

[...] a mercadificação da educação pública não é uma abstração, mas ocorre via sujeitos e processos. Trata-se de sujeitos individuais e coletivos que estão cada vez mais organizados, em redes do local ao global, com diferentes graus de influência e que falam de diferentes lugares: setor financeiro, organismos internacionais, setor governamental (PERONI, 2018, p. 214-215).

Diante do exposto, evidencia-se a necessidade na organização de movimentos que tensionem o conteúdo de qualidade educacional por um viés progressista, como o proposto pelo CNDE na integração do CAQ/CAQi no Fundeb (CAMPANHA NACIONAL PELO DIREITO À EDUCAÇÃO, 2020), para que um padrão mínimo de qualidade seja garantido para todas as crianças.

\section{Considerações finais}

O objetivo do presente artigo foi problematizar a perspectiva de qualidade educacional do GIFE no bojo da relação com o âmbito público a partir da OSD4. Nesta direção, verificou-se que no Brasil há uma proposição legal do princípio de qualidade e de um padrão de qualidade. Contudo, emerge um tensionamento acerca do seu conteúdo por 
grupos de interesses distintos. Neste sentido, em uma perspectiva ampla o direito a uma educação de qualidade parte do pressuposto da exigência mínima, frente ao Estado, de recursos no sentido de superar e promover oportunidades igualitárias a todas as crianças.

Para além disso, aferiu-se que o desdobramento do ODS4 no contexto brasileiro está comprometido pela não concretude do PNE 2014-2024. Este fato ocorre, entre outros desafios, especialmente, pela proposição da EC 95/2016. Sob este prisma, a perspectiva de qualidade do GIFE, a partir da ODS4, é a de qualidade voltada para o resultado. 0 GIFE associa a ODS4 à ODS17, a qual fomenta as parcerias entre o setor público e o privado. Ou seja, o grupo defende as parcerias no setor público para o alcance de qualidade atrelada à ODS4, contudo suas ações voltam-se para a qualidade somente na dimensão de resultados postos pelas avaliações externas, sua estratégia de ação é direcionada para a formação de professores e projetos e parcerias no âmbito da gestão. Desta forma, o currículo converge para as disciplinas dispostas nas avaliações e de acordo com o conteúdo do interesse de seus associados.

Assim, o movimento desta pesquisa foi agregar a discussão acerca da defesa e do tensionamento de um padrão de qualidade. No entendimento da qualidade que inclua dimensões essenciais, como recursos e insumos, e ampliadas para a garantia do direito educacional que inclua todas as crianças, para além das dimensões de acesso e permanência.

\section{Referências}

ADAMS, D. Defining Educational Quality. Arlington, VA, Institute for International Research, 1993.

ADRIÃO; T. SILVA, R. Public funding to private providers of compulsory education: crossed looks between Brazil and Portugal in the context of globalisations. Societies and Education, 18:4, 420-434, 2020.

AKKARI, A. Internacionalização das políticas educacionais: transformações e desafios. Petrópolis: Vozes, 2011.

BOAVENTURA, E. M. As formas de manifestação do Direito Educacional. Faculdade de Educação, São Paulo, v. 19, n. 2, p. 175-188, jul./dez. 1993.

BRASIL. [Constituição (1988)]. Constituição da República Federativa do Brasil. Rio de Janeiro: Roma Victor, 2002. 320 p. Disponível em: http://www.planalto.gov.br/ccivil 03/constituicao/constituicao.htm. Acesso em: 14 ago. 2020. 
BRASIL. Lei de Diretrizes e Bases para a Educação Nacional, LDBEN 9.496/1996.

BRASIL. Conselho Nacional de Educação (CNE). Câmara de Educação Básica (CEB). Parecer CNE/CEB no 8, aprovado em 5 de maio de 2010. Estabelece normas para aplicação do inciso IX do artigo 4o da Lei no 9.394/96 (LDB), que trata dos padrões mínimos de qualidade de ensino para a Educação Básica pública. 2010.

BRASIL. Lei Federal 13.005, de 25 de junho de 2014. Aprova o Plano Nacional de Educação - PNE e dá outras providências. Brasília, DF, 25. Jun. 2014.

CAMPANHA NACIONAL PELO DIREITO À EDUCAÇÃO (Brasil) (org.). CAQ e CAQi no PNE: quanto custa a educação pública de qualidade no Brasil? São Paulo: E-book, 2018. 206 p. Disponível em: http://www.custoalunoqualidade.org.br/pdf/quanto-custa-aeducacao-publica-dequalidade- no-brasil.pdf. Acesso em: 16 ago. 2020.

CAMPANHA NACIONAL PELO DIREITO À EDUCAÇÃO (Brasil) (org.). A situação do direito à educação e do Objetivo de Desenvolvimento Sustentável 4, Brasil, 2019. Disponível em: https://campanha.org.br/wpcontent/uploads/2019/07/HLPF RelatorioBrasil completo final.pdf. Acesso em: 16 ago. 2020 .

CAMPANHA NACIONAL PELO DIREITO À EDUCAÇÃO (Brasil) (org.) IV Relatório Luz da Sociedade Civil da Agenda 2030 de desenvolvimento sustentável, Brasil, 2020. Disponível em: https://gtagenda2030.org.br/relatorio-luz/relatorio-luz-2020/. Acesso em: 22 ago. 2020.

CARREIRA, D.; PINTO, J. M. R. Custo aluno-qualidade inicial: rumo à educação pública de qualidade no Brasil. São Paulo: Global; Campanha Nacional pelo Direito à Educação, 2007.

CURY, C. R. J. Direito à educação: direito à igualdade, direito à diferença. Cadernos de Pesquisa, São Paulo, n. 116, p. 245-262, jul. 2002.

FERRETI, M.; BARROS, M. SANTIAGO, G. (Org.) Censo GIFE 2018. São Paulo, SP: GIFE, 2019. Disponível em: file:///C:/Users/lenovo/Downloads/CENSO-GIFE-2018 -1aReimpressao-1\%20(2).pdf. Acesso em: 10 ago. 2020.

GENTILI, P.A.A.; SILVA, T.T. (orgs.) Neoliberalismo, Qualidade Total e Educação: Visões Críticas. Petrópolis, RJ: Vozes: p. 111-178, 1994.

GIFE. Grupo de Institutos, Fundações e Empresas. Site oficial, 2020. Disponível em: https://gife.org.br/. Acesso em: 10 ago. 2020.

HULME, D. Lessons from the Making of the MDGs: Human Development Meets Resultsbased Management in an Unfair World. IDS Bulletin, v. 41, n. 1, p. 15-25, 2010.

IPEA - INSTITUTO DE PESQUISA ECONÔMICA APLICADA. Cadernos ODS: assegurar a educação inclusiva e equitativa e de qualidade, e promover oportunidades de aprendizagem ao longo da vida para todas e todos, o que mostra o retrato do Brasil? 
Brasília, v. 24, 2019. Disponível em:

http://repositorio.ipea.gov.br/bitstream/11058/9349/1/Cadernos ODS Objetivo 4 As segurar $\% 20 \mathrm{a} \% 20$ educa $\%$ C3\%A7\%C3\%A3o $\% 20$ inclusiva $\% 20 \mathrm{e} \% 20$ equitativa $\% 20 \mathrm{e} \% 2$ 0de\%20qualidade.pdf. Acesso em: 05 ago. 2020.

ONU. ORGANIZAÇÃO DAS NAÇÕES UNIDAS. Transformando Nosso Mundo: A Agenda 2030 para o Desenvolvimento Sustentável. 2016. Disponível em:

http://www.itamaraty.gov.br/images/ed desenvsust/Agenda2030-completo-site.pdf. Acesso em: 04 ago. 2020.

PERONI, V. M. V. Múltiplas formas de materialização do privado na educação básica pública no Brasil: sujeitos e conteúdo da proposta. Currículo sem Fronteiras, v. 18, p. 1-27, 2018. Disponível em:

http://www.curriculosemfronteiras.org/vol18iss1articles/peroni.pdf. Acesso em: 07 ago. 2020.

PNUD - PROGRAMA DAS NAÇÕES UNIDAS PARA O DESENVOLVIMENTO BRASIL. Filantropia e os ODS: 0 investimento social privado brasileiro engajado na agenda global do desenvolvimento. 2017. Disponível em:

file:///C:/Users/lenovo/Downloads/Portuguese-Filantropia-e-os-ODS.pdf. Acesso em: 10 ago. 2020.

SHIROMA, E. O.; EVANGELISTA, O. Estado, Capital e Educação: Reflexões sobre hegemonia e Redes de Governança. Revista Educação e Fronteiras, Dourados/MS, v.4, n.11, p.21-38, mai./ago. 2014.

SHIROMA, E. O.; ZANARDINI, I. M. S. Estado e gerenciamento da educação para o desenvolvimento sustentável: recomendações do capital expressas na Agenda 2030.

Revista on-line de Política e Gestão Educacional, Araraquara, v. 24, n. esp. 1, p. 693714, ago. 2020. Disponível em: https://doi.org/10.22633/rpge.v24iesp1.13785. Acesso em: 20 out. 2020.

TOMASEVSKI, K. Indicadores del derecho a la educación. Revista IIDH, vol. 40, 2004.

UNESCO. Organização das Nações Unidas para a Educação, a Ciência e a Cultura.

Declaração de Incheon e Marco de ação da educação: rumo a uma educação de qualidade inclusiva e equitativa e à educação ao longo da vida para todos. Brasília, 2016. Disponível em:

http://www.mpsp.mp.br/portal/page/portal/cao civel/aa ppdeficiencia/aa ppd educa caoinclusiva/Declara \%C3\%A7\%C3\%A3o\%20de\%20Incheon $\% 20 \mathrm{e} \% 20 \mathrm{Marc0} \% 20 \mathrm{de} \%$ 20A\%C3\%A7\%C3\%A30\%20-\%20Educa\%C3\%A7\%C3\%A3o\%202030.pdf. Acesso em: 10 out. 2020.

XIMENES, S. B. 0 Conteúdo Jurídico do Princípio Constitucional da Garantia de Padrão de Qualidade do Ensino: uma contribuição desde a teoria dos direitos fundamentais.

Educação e Sociedade, dez. 2014a, vol.35, no.129, p.1027-1051.

XIMENES, S. B. Padrão de qualidade do ensino: desafios institucionais e base para a construção de uma teoria jurídica. São Paulo, 2014b. 428f. (Doutorado em Direito) 
SAKATA, K. L. A Qualidade Educacional: da Agenda 2030 para o desenvolvimento Sustentável ao Grupo de Institutos, Fundações e Empresas (GIFE)

Programa de Pós-Graduação em Direito da Faculdade de Direito da Universidade de São Paulo, São Paulo, 2014b. 

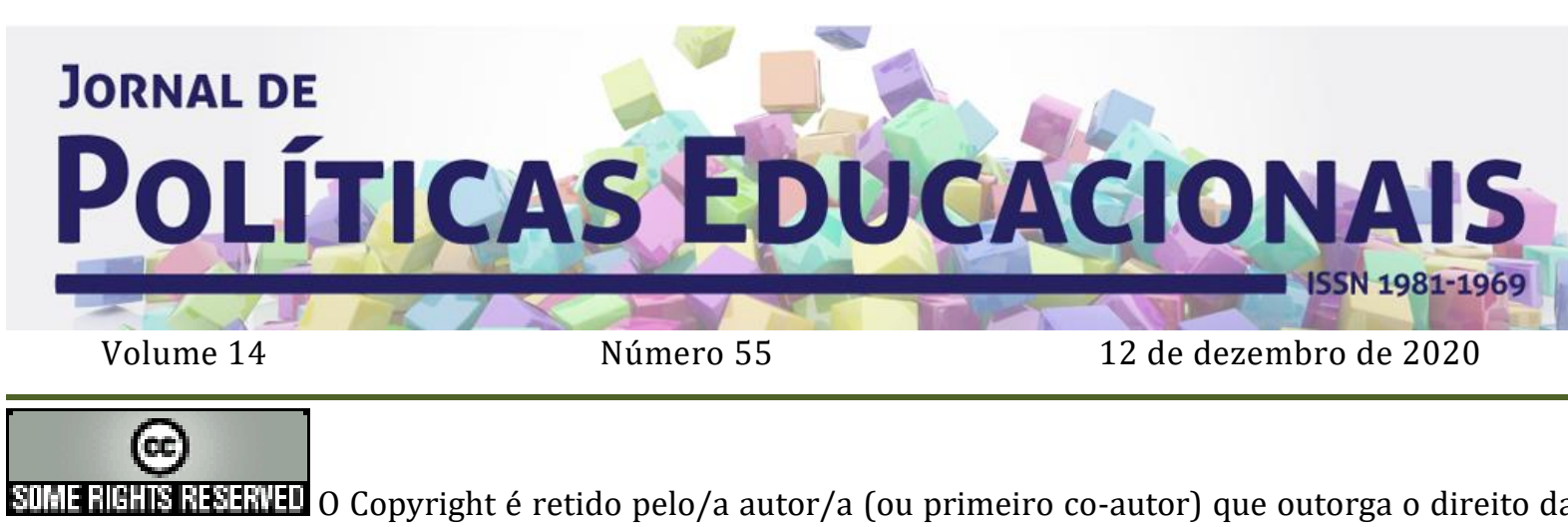

Copright é retido pelo/a autor/a (ou pr primeira publicação ao Jornal de Políticas Educacionais. Mais informação da licença de Creative Commons encontram-se em http://creativecommons.org/licenses/by-nc-nd/2.5. Qualquer outro uso deve ser aprovado em conjunto pelo/s autor/es e pelo periódico.

JORNAL DE POLÍTICAS EDUCACIONAIS é uma publicação do Núcleo de Políticas Educacionais do Setor de Educação da Universidade Federal do Paraná - NuPE/UFPR, em consórcio com a Linha de Pesquisa em Políticas Educacionais do Programa de Pós-Graduação em Educação - PPGE/UFPR, que aceita colaboração, reservando-se o direito de publicar ou não o material espontaneamente enviado à redação. As colaborações devem ser enviadas ao NuPE/UFPR, conforme orientações contidas nas páginas do periódico na internet: http://revistas.ufpr.br/ipe.

\author{
Indexação: \\ BBE - Biblioteca Brasileira de Educação (MEC/INEP) \\ Clase (Base de Datos Bibliográfica de Revistas de Ciencias Sociales y Humanidades) \\ Diadorim - Diretório de Política de Acesso Aberto das Revistas Científicas Brasileiras (IBICT) \\ Google Scholar \\ Index Copernicus \\ Portal de Periódicos (CAPES) \\ SER - Sistema Eletrônico de Revistas da Universidade Federal do Paraná (SER/UFPR) \\ Sumários de Revistas Brasileiras (FUNPEC-RP) \\ DRJI - Directory of Research Journals Indexing
}

(Periódico integralmente disponível apenas em via eletrônica)

Jornal de Políticas Educacionais / Núcleo de Políticas Educacionais da Universidade Federal do Paraná NuPE/UFPR - v.1, n. 1 (1ํo semestre de 2007) - Curitiba: NuPE/UFPR.

Volume 14, número 55 - Dezembro de 2020

ISSN 1981-1969

1. Educação - Periódicos. 2. Política Educacional - Periódicos. I. NuPE/UFPR

Comitê Editorial:

Elisângela Scaff (UFPR)

Daniela de Oliveira Pires (UFPR)

Conselho Editorial:

Andréa Barbosa Gouveia (UFPR - Brasil), Cesar Tello (Universidad Nacional Tres Febrero, Argentina), Fernanda Saforcada (Universidad de Buenos Aires - UBA - Argentina), Gladys Beatriz Barreyro (USP Brasil), Gustavo Enrique Fischman, (Arizona State University - USA), Jefferson Mainardes (UEPG - Brasil), João Ferreira de Oliveira (UFG - Brasil), Juca Gil (UFRGS - Brasil), Luiz Souza Júnior (UFPB - Brasil), Ney 
SAKATA, K. L. A Qualidade Educacional: da Agenda 2030 para o desenvolvimento Sustentável ao Grupo de Institutos, Fundações e Empresas (GIFE)

Cristina Monteiro de Oliveira (UFPA - Brasil), Nicolás Bentancur, (Universidad de la República de Uruguay), Robert Verhine (UFBA - Brasil), Rosana Cruz (UFPI - Brasil), Rubens Barbosa Camargo (USP - Brasil), Sebastián Donoso Díaz (Universidad de Talca - Chile), TheresaAdrião (UNICAMP - Brasil), Vera Peroni (UFRGS - Brasil).

Créditos e Agradecimentos:

Revisão de Língua Portuguesa, Abstract e Resumen: PROGRAMA DE APOIO ÀS PUBLICAÇõES CIENTÍFICAS PERIÓDICAS DA UFPR

Arte e diagramação: TIAGO TAVARES (tiagotav@gmail.com)

Jornal de Políticas Educacionais

Universidade Federal do Paraná

Setor de Educação

Núcleo de Políticas Educacionais - NuPE/UFPR

Avenida Sete de Setembro, 2645

2 andar, Sala 213

80.230-010 - Curitiba - PR - Brasil

Tel.: 41-3535-6264

jpe@ufpr.br

http://revistas.ufpr.br/jpe 